\title{
Optimization, characterization and in Vitro evaluation of entomopathogenic fungal exopolysaccharides as prebiotic
}

\author{
Wai Prathumpai ${ }^{1,}$, Pranee Rachathewee ${ }_{4}$, Sutamat Khajeeram ${ }^{2}$, Jean-Jacques Sanglier ${ }^{3}$, \\ Pariyada Tanjak ${ }^{4}$, Pawadee Methacanon ${ }^{4}$ \\ ${ }^{1}$ National Center for Genetic Engineering and Biotechnology (BIOTEC), National Science and Technology Development Agency, 113 \\ Thailand Science Park, Klong Nueng, Klong Luang, Pathum Thani 12120, Thailand \\ ${ }^{2}$ Department of Biotechnology, Thammasat University, Klong Nueng, Klong Luang, Pathumthani 12120, Thailand \\ ${ }^{3}$ Novartis Institute for BioMedical Research Basel, Natural Products Unit, Novartis Pharma AG, Basel, Switzerland \\ ${ }^{4}$ National Metal and Materials Technology Center (MTEC), 114 Thailand Science Park, Paholyothin Rd., Klong Nueng, Klong Luang, \\ Pathum Thani 12120, Thailand
}

\section{Email address:}

wai.pra@biotec.or.th(W.Prathumpai)

\section{To cite this article:}

Wai Prathumpai, Pranee Rachathewee, Sutamat Khajeeram, Jean-Jacques Sanglier, Pariyada Tanjak, Pawadee Methacanon. Optimization, Characterization and In Vitro Evaluation of Entomopathogenic Fungal Exopolysaccharides as Prebiotic. Advances in Biochemistry.

Vol. 1, No. 2, 2013, pp. 13-21. doi: 10.11648/j.ab.20130102.12

\begin{abstract}
Optimization of exopolysaccharides (EPS) produced by three strains of entomopathogenic fungi (Beauveria bassiana BCC 2692, Ophiocordyceps dipterigena BCC 2073, and Paecilomyces tenuipes BCC 2656) was carried out together with analyses of their prebiotic properties. B. bassiana BCC 2692 produced $6.27 \pm 0.22 \mathrm{~g} / \mathrm{L}$ EPS on optimal medium using two-level fractional factorial design and $4.7 \mathrm{~g} / \mathrm{L}$ EPS in bioreactor. EPS productions of O. dipterigena BCC 2073 were $13.2 \mathrm{~g} / \mathrm{L}$ and $41.2 \mathrm{~g} / \mathrm{L}$ in shake flask and bioreactor, respectively. For P. tenuipes BCC $2656,1.47 \pm 0.21 \mathrm{~g} / \mathrm{L}$ EPS in shake flask and $28.1 \mathrm{~g} / \mathrm{L}$ EPS in bioreactor were obtained. These EPS were previously characterized as glucan with differences in molecular weights and degree of branching. They were resistant to hydrolysis by both hydrochloric acid and porcine pancreatic $\alpha$-amylase. Furthermore, when used as the sole carbon source, all three types of EPS supported growth in vitro of two different probiotic bacteria (Lactobacillus acidophilus BCC 13839 and bifid bacterium animals ATCC 25527). A constant viability of L. acidophilus BCC 13839 was maintained throughout the cultivation period (48 hours) on all three entomopatogenic fungal EPS. All EPS also supported better growth and maintained longer growth period of B. animalis ATCC 25527 than glucose or inulin. Thus these entomopathogenic fungi EPS are promising candidates in prebiotic industry, expanding the pool of current commercial prebiotics.
\end{abstract}

Keywords: Exopolysaccharide, Glucan, Prebiotic, Probiotic, Entomopathogenic Fungi

\section{Introduction}

It is now well established that gastrointestinal diseases caused by the increase in gastrointestinal pathogens can often be diminished by promotion of the growth of probiotics, such as lactic acid bacteria and bifidobacteria $[1-2,12-14,18,27-28,32,35-37,41]$, thus, there is a great deal of interest in the use of prebiotics. Prebiotics, non-digestible compounds in animals and humans, consist of a group of oligosaccharides that are able to stimulate growth of an essential consortium of bacteria in gastrointestinal tract $[6-8,12,15-16,20,22,30,33-34,37$, 39]. Moreover, good prebiotics are required to resist stomach acid hydrolysis, be fermented by the intestinal microbiota, and selectively stimulate growth of useful intestinal bacteria $[7-8,12,15-16,22,30,33-34,37]$. The population of probiotics in the human's (and animal) gut system can be increased by the consumption of appropriate prebiotics [3, 8, 12, 22, 35-37], which include oligosaccharides, such as inulin, fructo-oligosaccharides, galacto-oligosaccharides, gluco-oligosaccharides, and 
xylo-oligosaccharides [1-3, 9-10, 13-16, 20, 29, 32, 39, 41]. There are also several types of prebiotics that have been studied for their functions to promote growth of probiotics $[9-10,18,27,29,38]$. However, current prebiotics are limited in their efficacies due to their persistences to the distal colon, while the microbiota known to have saccharolytic metabolism are predominantly in the proximal colon [7-8, 33-34, 37, 39].

Clearly, there are several groups of microorganisms producing exopolysaccharides (EPS) with different properties and applications, such as antitumor agents $[5$, 31], food packaging materials [25], and wound dressing materials $[23,26]$. In particular, EPS produced by fungi serve to protect their cells against desiccation, phagocytosis and phage attack, toxic compounds, predation by protozoans, and osmotic stress, as well as in cellular recognition [42]. There are several reports of prebiotics produced from natural resources, mostly from plants [15, 21], however, no studies on exopolysaccharides from entomopathogenic fungi with their prebiotic properties have been reported. Hence, EPS from fungi are attractive as an alternative source of prebiotics apart from their abundance and diversity in chemical structure.

In this study, prebiotic activities of the EPS secreted from three entomopathogenic fungi, namely, Beauveria bassiana BCC 2692, Ophiocordyceps dipterigena BCC 2073, and Paecilomyces tenuipes BCC 2656 were investigated. In addition, the optimization of the EPS production was carried out.

\section{Materials and Methods}

\subsection{Fungal Strains}

Entomopathogenic fungi, Beauveria bassiana BCC 2692, Ophiocordyceps dipterigena BCC 2073, and Paecilomyces tenuipes BCC 2656, were obtained from BIOTEC Culture Collection, National Center for Genetic Engineering and Biotechnology, Thailand.

\subsection{Probiotic Bacterial Strains}

Lactobacillus acidoplilus BCC 13839 and Bifidobacterium animalis ATCC 25527 were used as probiotic bacteria for the evaluation of their growths on different EPS in comparison with a commercial prebiotic (inulin; Bio Basic Inc., Toronto, Canada).

\subsection{Inoculum Preparation}

B. bassiana BCC 2692, O. dipterigena BCC 2073, and $P$. tenuipes BCC 2656 were grown initially on potato dextrose agar (PDA) (Becton, Dickinson and company, MD, USA) at $25{ }^{\circ} \mathrm{C}$ for 5-7 days. An agar block $\left(1 \mathrm{~cm}^{3}\right)$ containing the growing culture was cut into small pieces and transferred to $25 \mathrm{~mL}$ of potato dextrose broth (PDB) (Becton, Dickinson and company, MD, USA) and incubated with shaking (200 rpm) for 5-7 days at $25^{\circ}$ C. L. acidophilus BCC 13839 and B. animalis ATCC 25527 were pre-grown in MRS broth (Merck, Germany) and Difco ${ }^{\mathrm{TM}}$ Reinforced Clostridial medium respectively, at $37^{\circ} \mathrm{C}$ for $24-48 \mathrm{~h}$.

\subsection{Fermentation Conditions}

\subsubsection{Optimization of EPS Production}

A full factorial design was used to determine the optimal carbon and nitrogen sources [19]. Twenty g/L carbon sources (galactose, glucose, lactose, maltose, mannose, sucrose, and fructose) and $10 \mathrm{~g} / \mathrm{L}$ nitrogen sources $\left(\mathrm{NH}_{4} \mathrm{H}_{2} \mathrm{PO}_{4},\left(\mathrm{NH}_{4}\right)_{2} \mathrm{SO}_{4}\right.$, malt extract, peptone, yeast extract, meat extract, corn steep solid, $\mathrm{NaNO}_{3}, \mathrm{NH}_{4} \mathrm{NO}_{3}$, and tryptone) were combined in a basal medium $(0.5 \mathrm{~g} / \mathrm{L}$ $\mathrm{KH}_{2} \mathrm{PO}_{4}, 0.2 \mathrm{~g} / \mathrm{L} \mathrm{K}_{2} \mathrm{HPO}_{4}, 0.2 \mathrm{~g} / \mathrm{L} \mathrm{MgSO}_{4} \cdot 7 \mathrm{H}_{2} \mathrm{O}, 0.14 \mathrm{~g} / \mathrm{L}$ $\mathrm{MnSO}_{4} \cdot \mathrm{H}_{2} \mathrm{O}$, and $1 \mathrm{~mL} / \mathrm{L}$ vitamin solution (Blackmore, NSW, Australia)). Experiments were conducted in duplicate. The influence of 6 quantitative factors (carbon (sugar) concentration, nitrogen concentration (combination of four nitrogen sources) and trace element solution) on EPS production was evaluated using a fractional factorial design at 2 levels [19] conducted in duplicate with 3 center points. The optimal condition for each fungal strain selected from the fractional factorial design then was evaluated in a $5-\mathrm{L}$ fermenter in order to produce sufficient exopolysaccharides (EPS) for further experiments.

As the full factorial design at 2 levels with 6 factors requires an evaluation of 64 combinations, a reduced design, known as fractional factorial, with only 32 combinations was used with 3 center points [19]. In these experiments, the production of biopolymer was the main output of the process. In addition, biopolymer and biomass were taken into consideration as primary responses in order to evaluate the relationship between growth and production. Design Expert software (Version 7.0.b1.1, Stat-Ease Inc., and Minneapolis, USA) was used for experimental design selection and data analysis.

\subsubsection{Entomopathogenic Fungal EPS Production for Prebiotic Evaluation}

The optimized medium used in the 5-L fermented (Marubishi Co., Ltd., Pathumthani, Thailand), with a working volume of $4 \mathrm{~L}$, for B. bassiana BCC 2692 consisted of fructose $60 \mathrm{~g} / \mathrm{L}$, malt extract $10 \mathrm{~g} / \mathrm{L}$, peptone $10 \mathrm{~g} / \mathrm{L}$ and yeast extract $10 \mathrm{~g} / \mathrm{L}$; for $O$. dipterigena $\mathrm{BCC}$ 2073; glucose $60 \mathrm{~g} / \mathrm{L}$, malt extract $14 \mathrm{~g} / \mathrm{L}$; and for $P$. tenuipes BCC 2656; glucose $60 \mathrm{~g} / \mathrm{L}$, corn steep solid $15 \mathrm{~g} / \mathrm{L}$. The basal medium composition for all recipes contained 0.5 $\mathrm{g} / \mathrm{L} \mathrm{KH}_{2} \mathrm{PO}_{4}, 0.2 \mathrm{~g} / \mathrm{L} \mathrm{K} \mathrm{HPO}_{4}, 0.2 \mathrm{~g} / \mathrm{L} \mathrm{MgSO}{ }_{4} \cdot 7 \mathrm{H}_{2} \mathrm{O}, 0.14$ $\mathrm{g} / \mathrm{L} \mathrm{MnSO}_{4} \cdot \mathrm{H}_{2} \mathrm{O}$, and $1 \mathrm{~mL} / \mathrm{L}$ vitamin solution (Blackmore). The vitamin complex consisted of $75 \mathrm{mg}$ vitamin B1 (thiamine hydrochloride), $10 \mathrm{mg}$ vitamin B2 (riboflavin), $50 \mathrm{mg}$ nicotinamide, $25 \mathrm{mg}$ calcium pantothenate, $10 \mathrm{mg}$ vitamin B6 (pyridoxine hydrochloride), $25 \mathrm{mcg}$ vitamin B12 (cyanocobalamin), $15 \mathrm{mcg}$ biotin, $500 \mathrm{mg}$ vitamin C (derived from ascorbic acid $260 \mathrm{mg}$ and calcium ascorbate 
$290.5 \mathrm{mg}$ ), $10 \mathrm{mg}$ choline bitartrate, $10 \mathrm{mg}$ inositol, $10 \mathrm{mg}$ zinc amino acid chelate (zinc $2 \mathrm{mg}$ ), $175 \mathrm{mg}$ calcium phosphate, and $75 \mathrm{mg}$ magnesium phosphate. Trace element solution contained (per L) $14.3 \mathrm{~g}$ of $\mathrm{ZnSO}_{4} \cdot \mathrm{H}_{2} \mathrm{O}$, $2.5 \mathrm{~g}$ of $\mathrm{CuSO}_{4} \cdot 5 \mathrm{H}_{2} \mathrm{O}, 0.5 \mathrm{~g}$ of $\mathrm{NiCl}_{2} \cdot 6 \mathrm{H}_{2} \mathrm{O}$ and $13.8 \mathrm{~g}$ of $\mathrm{FeSO}_{4} \cdot \mathrm{H}_{2} \mathrm{O}$. Fungal seed culture $(10 \% \mathrm{v} / \mathrm{v})$ was transferred to each fermenter and the culture was agitated at $300 \mathrm{rpm}$ and aerated at $1 \mathrm{vvm}$, with no adjustment of $\mathrm{pH}$.

\subsection{EPS preparation}

Culture filtrate was mixed with four volumes of $95 \%$ ethanol, stirred vigorously for $10-15 \mathrm{~min}$. and kept at $20{ }^{\circ} \mathrm{C}$ for at least $12 \mathrm{~h}$. Precipitated EPS was sedimented at $10,000 \mathrm{~g}$ for $20 \mathrm{~min}$ and lyophilized. EPS was redissolved in distilled water (30-50 g wet weight per1 L of distilled water) and insoluble material was removed by sedimentation as described above. The supernatant was then dialyzed (2 kDa molecular weight cut-off; Spectrum Laboratories Inc., USA) against $4 \mathrm{~L}$ of distilled water for $24 \mathrm{~h}$ and lyophilized once more.

\subsection{EPS Characterization}

\subsubsection{Molecular Weight Determination}

The average molecular weight of EPS was determined using gel-permeation chromatography (GPC, Waters 600E; Waters, MA, USA), equipped with a refractive index (RI) detector and Ultrahydrogel column $(300 \times 7.8 \mathrm{~mm}$ diameter; Waters, USA) calibrated with dextran standard molecular weight markers $(4,400$ to $401,000 \mathrm{Da})$. Injection volume was $20 \mu \mathrm{L}$ and the sample was eluted with $0.05 \mathrm{M}$ sodium bicarbonate buffer at a flow rate of $0.6 \mathrm{~mL} / \mathrm{min}$.

\subsection{2. ${ }^{13}$ C-NMR Spectroscopy}

${ }^{13} \mathrm{C}$-NMR spectra of samples in $0.1 \mathrm{M} \mathrm{NaOD}(50 \mathrm{mg} / \mathrm{mL})$ were recorded at temperature of $298 \mathrm{~K}$ using AVANCE 300 MHz Digital NMR spectrometer (Bruker Biospin, AV-500, Germany) at a frequency of $125 \mathrm{MHz}$. Typical parameters used were: number of scans 20,000, relaxation delay $1 \mathrm{~s}$, spin rate $25 \mathrm{~Hz}$, spectrum size $32 \mathrm{~K}$ and time domain points $32 \mathrm{~K}$.

\subsubsection{Probiotic Cultivation of L. Acidophilus BCC 13839 and B. Animals ATCC 25527 on EPS as Carbon Source}

L. acidophilus BCC 13839 and B. animalis ATCC 25527 were cultured in $1 \mathrm{~L}$ fermenter (Biostat Q, B. Braun, Germany) with a working volume of $700 \mathrm{~mL}$ for $48 \mathrm{~h}$ at 37 ${ }^{\circ} \mathrm{C}$, agitation of $100 \mathrm{rpm}$, and no aeration. Medium used for L. acidophilus BCC 13839 and B. animalis ATCC
25527 was MRS and Clostridial medium, respectively. 10 $\mathrm{g} / \mathrm{L}$ of each EPS from $B$. bassiana BCC 2692, $O$. dipterigena BCC 2073, P. tenuipes BCC 2656, glucose or inulin were used as a carbon source.

\subsubsection{Biomass and Cell Viability Measurements}

Turbidity of cultures was determined by measuring absorbance at $600 \mathrm{~nm}$. Number of viable cells was determined by serial dilutions in fresh medium (MRS for L. acidophilus BCC 13839 and Difco ${ }^{\mathrm{TM}}$ Reinforced Clostridial for $B$. animalis ATCC 25527) which was incubated at $37{ }^{\circ} \mathrm{C}$ for $24-48 \mathrm{~h}$. Colony forming units were determined in Petri-dishes having 30-300 colonies.

\subsubsection{Lactic Acid Measurement}

Probiotic cell cultures were centrifuged at $10,000 \mathrm{~g}$ for $10 \mathrm{~min}$ and supernatants were filtered through $0.22 \mu \mathrm{m}$ filters. Filtrates were subjected to HPLC analysis using an Aminex column (Bio-Rad, Hercules, CA) at $65^{\circ} \mathrm{C}$, using 5 $\mathrm{mM} \mathrm{H}_{2} \mathrm{SO}_{4}$ as a mobile phase at a flow rate of $0.6 \mathrm{~mL} / \mathrm{min}$ and a pressure of 1000-1200 psi. Lactic acid was detected with a refract meter (Waters 410 Differential Refract meter Detector, Millipore Corp., Milford, MA, USA) at retention time of 12.3-12.4 min.

\subsection{Digestibility Assay}

\subsubsection{Gastric Juice Hydrolysis}

In order to mimic the acid condition of the stomach, EPS were incubated with $0.1 \mathrm{M} \mathrm{HCl}$ at $37^{\circ} \mathrm{C}$ and samples $(0.5$ $\mathrm{mL}$ ) were interval taken at $0,1,2,4$, and $6 \mathrm{~h}$ for determination of liberated reducing sugars using dinitrosalicylic acid (DNS) assay using glucose as standard [4].

\subsubsection{Enzymatic hydrolysis}

Sensitivity of EPS to porcine pancreatic $\alpha$-amylase (EC. 3.2.1.1) (Sigma-Aldrich) was evaluated by mixing $1 \mathrm{~mL}$ of EPS (1\% w/v of sodium phosphate buffer $\mathrm{pH} 7)$ with an equal volume of enzyme solution ( 2 units $/ \mathrm{mL}$ of $20 \mathrm{mM}$ sodium phosphate buffer containing $6.7 \mathrm{mM}$ sodium chloride) and an equal volume of color reagent (dinitrosalicylic acid, DNS), $1 \mathrm{~mL}$ ), and the mixture was incubated at $37{ }^{\circ} \mathrm{C}$ for $0,1,2,4$ and $6 \mathrm{~h}$, after which time the reaction was terminated by heating in boiling water for $15 \mathrm{~min}$. The reaction mixture was cooled to room temperature and $9 \mathrm{~mL}$ of deionized water were added. The amount of reducing sugar was measured at $540 \mathrm{~nm}$, using glucose as standard.

Table 1. EPS and biomass production of B. bassiana BCC 2692 using a two-level fractional factorial design with 6 factors $\left(2^{n-1}\right)$

\begin{tabular}{cccccccc}
\hline $\begin{array}{c}\text { Fructose } \\
(\mathbf{g} / \mathbf{L})\end{array}$ & $\begin{array}{c}\text { Malt extract } \\
(\mathbf{g} / \mathbf{L})\end{array}$ & $\begin{array}{c}\text { peptone } \\
(\mathbf{g} / \mathbf{L})\end{array}$ & $\begin{array}{c}\mathbf{N a N O}_{3} \\
(\mathbf{g} / \mathbf{L})\end{array}$ & $\begin{array}{c}\text { Yeast extract } \\
(\mathbf{g} / \mathbf{L})\end{array}$ & $\begin{array}{c}\text { Trace } \\
\text { solution } \\
(\mathbf{m L} / \mathbf{L})\end{array}$ & $\begin{array}{c}\mathbf{E P S} \\
(\mathbf{g} / \mathbf{L})\end{array}$ & $\begin{array}{c}\text { Biomass } \\
(\mathbf{g} / \mathbf{L})\end{array}$ \\
\hline 20 & 0 & 0 & 0 & 0 & 1 & 0 & $1.78 \pm 1.74$ \\
60 & 0 & 0 & 0 & 10 & 1 & 0 & $4.71 \pm 1.03$ \\
20 & 10 & 0 & 0 & 10 & 4 & 0 & $14.77 \pm 0.56$ \\
\hline
\end{tabular}




\begin{tabular}{cccccccc}
\hline 60 & 10 & 0 & 0 & 0 & 4 & 0 & $1.89 \pm 0.03$ \\
20 & 0 & 15 & 0 & 10 & 4 & 0 & $6.48 \pm 1.00$ \\
60 & 0 & 15 & 0 & 0 & 4 & 0 & $4.09 \pm 1.12$ \\
20 & 10 & 15 & 0 & 0 & 1 & $2.05 \pm 0.08$ & $27.27 \pm 8.73$ \\
60 & 10 & 15 & 0 & 10 & 1 & $6.27 \pm 0.22$ & $27.77 \pm 10.41$ \\
20 & 0 & 0 & 5 & 0 & 4 & $0.93 \pm 0.04$ & $7.28 \pm 3.27$ \\
60 & 0 & 0 & 5 & 10 & 4 & 0 & $4.18 \pm 0.69$ \\
20 & 10 & 0 & 5 & 10 & 1 & $2.69 \pm 0.33$ & $17.92 \pm 0.01$ \\
60 & 10 & 0 & 5 & 0 & 1 & $0.47 \pm 0.66$ & $4.60 \pm 0.35$ \\
20 & 0 & 15 & 5 & 10 & 1 & $0.29 \pm 0.25$ & $9.49 \pm 3.09$ \\
60 & 0 & 15 & 5 & 0 & 1 & 0 & $7.38 \pm 0.14$ \\
20 & 10 & 15 & 5 & 0 & 4 & $2.27 \pm 0.06$ & $22.40 \pm 1.06$ \\
60 & 10 & 15 & 5 & 10 & 4 & $3.50 \pm 1.40$ & $28.09 \pm 0.84$ \\
40 & 5 & 7.5 & 2.5 & 5 & 2.5 & $5.57 \pm 0.97$ & $23.72 \pm 3.03$ \\
\hline
\end{tabular}

\section{Results}

\subsection{Optimization of EPS Production}

Optimal EPS production from B. bassiana BCC 2692 $(6.27 \pm 0.22 \mathrm{~g} / \mathrm{L})$ using two-level fractional factorial design was achieved on fructose $60 \mathrm{~g} / \mathrm{L}$, malt extract $10 \mathrm{~g} / \mathrm{L}$, peptone $15 \mathrm{~g} / \mathrm{L}$, yeast extract $10 \mathrm{~g} / \mathrm{L}$ and trace elements solution $1.0 \mathrm{~mL} / \mathrm{L}$ (Table 1). For P. tenuipes BCC 2656, the highest EPS production $(1.47 \pm 0.21 \mathrm{~g} / \mathrm{L})$ was on glucose 60 $\mathrm{g} / \mathrm{L}$, corn steep solid $15 \mathrm{~g} / \mathrm{L}$ and trace elements solution 1.0 $\mathrm{mL} / \mathrm{L}$ (Table 2). Furthermore, the highest EPS production of $O$. dipterigena $\mathrm{BCC} 2073$ was $13.2 \pm 0.74 \mathrm{~g} / \mathrm{L}$ on glucose $60 \mathrm{~g} / \mathrm{L}$ and malt extract $14 \mathrm{~g} / \mathrm{L}$ at $25{ }^{\circ} \mathrm{C}$ [19]. The optimal medium composition obtained from the fractional factorial design (Table 3) was evaluated in a 5-L fermenter. After optimization, B. bassiana BCC 2692 produced $4.7 \mathrm{~g} / \mathrm{L}$ EPS, whereas O. dipterigena BCC 2073 and P. tenuipes BCC 2656 on glucose-supplemented medium produced higher amounts of EPS (41.2 and $28.1 \mathrm{~g} / \mathrm{L}$, respectively).

\subsection{EPS Characteristics}

Previously we have shown that these fungal EPS belong to the group of $\beta$-glucans consisting of $\beta-(1 \rightarrow 3)$ linkage as the main chain with $\beta-(1 \rightarrow 6)$ as branch points
[26]. In this study, analysis of the molecular weight showed that the three EPS samples were significantly different, ranging from 4 to $2310 \mathrm{kDa}$, with that of $P$. tenuipes $\mathrm{BCC}$ 2656 being the lowest (in the range of oligosaccharides), and that of B. bassiana BCC 2692 having the largest size with a bimodal distribution (49 and $2310 \mathrm{kDa}$ ) (Table 3).

The presence of $\beta$-D- $(1 \rightarrow 3,1 \rightarrow 6)$-linked glucans in EPS from O. dipterigena $\mathrm{BCC} 2073$ and P. tenuipes $\mathrm{BCC}$ 2656 were confirmed by ${ }^{13} \mathrm{C}-\mathrm{NMR}$ (Figure 1). The EPS of O. dipterigena $\mathrm{BCC} 2073$ exhibited two anomeric carbon signals at 103 and $100 \mathrm{ppm}$, clearly showing the presence of $\beta$ - and $\alpha$-glucans with a ratio of 2:1. On the other hand, in the spectrum of $P$. tenuipes BCC 2656 EPS, the $\beta$-configuration of D-glucosyl residues was evident from the presence of only one anomeric peak at $106 \mathrm{ppm}$. The other carbon signals in the spectra were tentatively assigned as shown, although some signals were shifted compared to the literature values [11, 17], probably due to different substituents and degree of branching. It is worth noting that the ${ }^{13} \mathrm{C}$-NMR spectrum of EBP from $B$. bassiana $\mathrm{BCC}$ 2692 was similar to that from $O$. dipterigena $\mathrm{BCC} 2073$ but was slightly more complicated due to the existence of two constituents as indicated by MW evaluation (data not shown).

Table 2. EPS and biomass production of P. tenuipes BCC 2656 using a two-level fractional factorial design with 6 factors $\left(2^{n-1}\right)$

\begin{tabular}{cccccccc}
\hline $\begin{array}{c}\text { Glucose } \\
(\mathbf{g} / \mathbf{L})\end{array}$ & $\begin{array}{c}\text { Malt extract } \\
(\mathbf{g} / \mathbf{L})\end{array}$ & $\begin{array}{c}\mathbf{N a N O}_{3} \\
(\mathbf{g} / \mathbf{L})\end{array}$ & $\begin{array}{c}\mathbf{N H}_{\mathbf{4}} \mathbf{N O}_{3} \\
(\mathbf{g} / \mathbf{L})\end{array}$ & $\begin{array}{c}\text { Corn steep solid } \\
(\mathbf{g} / \mathbf{L})\end{array}$ & $\begin{array}{c}\text { Trace } \\
\text { solution } \\
(\mathbf{m L} / \mathbf{L})\end{array}$ & $\begin{array}{c}\text { EPS } \\
(\mathbf{g} / \mathbf{L})\end{array}$ & $\begin{array}{c}\text { Biomass } \\
(\mathbf{g} / \mathbf{L})\end{array}$ \\
\hline 20 & 0 & 0 & 0 & 0 & 1 & $0.06 \pm 0.08$ & $2.53 \pm 0.01$ \\
60 & 0 & 0 & 0 & 15 & 1 & $\mathbf{1 . 4 7 \pm 0 . 2 1}$ & $14.87 \pm 8.60$ \\
20 & 10 & 0 & 0 & 15 & 4 & $1.09 \pm 0.42$ & $13.79 \pm 0.16$ \\
60 & 10 & 0 & 0 & 0 & 4 & $0.22 \pm 0.01$ & $6.55 \pm 0.71$ \\
20 & 0 & 5 & 0 & 15 & 4 & $0.59 \pm 0.01$ & $10.26 \pm 0.08$ \\
60 & 0 & 5 & 0 & 0 & 4 & 0 & $5.23 \pm 1.21$ \\
\hline
\end{tabular}




\begin{tabular}{|c|c|c|c|c|c|c|c|}
\hline 20 & 10 & 5 & 0 & 0 & 1 & $0.26 \pm 0.02$ & $4.70 \pm 0.11$ \\
\hline 60 & 10 & 5 & 0 & 15 & 1 & $0.59 \pm 0.83$ & $25.70 \pm 4.42$ \\
\hline 20 & 0 & 0 & 5 & 0 & 4 & $0.19 \pm 0.07$ & $3.29 \pm 0.07$ \\
\hline 60 & 0 & 0 & 5 & 15 & 4 & 0 & $21.34 \pm 1.41$ \\
\hline 20 & 10 & 0 & 5 & 15 & 1 & 0 & $17.05 \pm 0.39$ \\
\hline 60 & 10 & 0 & 5 & 0 & 1 & 0 & $5.08 \pm 1.32$ \\
\hline 20 & 0 & 5 & 5 & 15 & 1 & 0 & $12.47 \pm 2.02$ \\
\hline 60 & 0 & 5 & 5 & 0 & 1 & 0 & $2.86 \pm 0.33$ \\
\hline 20 & 10 & 5 & 5 & 0 & 4 & $0.34 \pm 0.48$ & $4.09 \pm 0.83$ \\
\hline 60 & 10 & 5 & 5 & 15 & 4 & $0.30 \pm 0.42$ & $25.69 \pm 1.07$ \\
\hline 40 & 5 & 2.5 & 2.5 & 7.5 & 2.5 & $0.39 \pm 0.53$ & $18.82 \pm 9.36$ \\
\hline
\end{tabular}

Table 3. Characteristics of EPS from three entomopathogenic fungi

\begin{tabular}{|c|c|c|c|}
\hline Fungus & $\begin{array}{c}\text { Molecular weight at peak } \\
(\mathrm{Mp}, \mathrm{kDa})\end{array}$ & Optimized mediuma & $\begin{array}{c}\text { Production in } 5 \mathrm{~L} \text { fermentor } \\
(\mathrm{g} / \mathrm{L})\end{array}$ \\
\hline B. bassiana BCC 2692 & 2310 and 49 & $\begin{array}{l}\text { fructose } 60 \mathrm{~g} / \mathrm{L} \text {, malt extract } 10 \mathrm{~g} / \mathrm{L} \text {, peptone } 15 \\
\mathrm{~g} / \mathrm{L} \text {, yeast extract } 10 \mathrm{~g} / \mathrm{L}\end{array}$ & $4.7^{\mathrm{a}}$ \\
\hline O. dipterigena $\mathrm{BCC} 2073$ & 590 & glucose $60 \mathrm{~g} / \mathrm{L}$, malt extract $14 \mathrm{~g} / \mathrm{L}$ & $41.2^{b}$ \\
\hline P. tenuipes BCC 2656 & 4.3 & glucose $60 \mathrm{~g} / \mathrm{L}$, corn steep solid $15 \mathrm{~g} / \mathrm{L}$ & $28.1^{\mathrm{a}}$ \\
\hline
\end{tabular}

${ }^{a}$ Basal medium $=0.5 \mathrm{~g} / \mathrm{L} \mathrm{KH}_{2} \mathrm{PO}_{4}, 0.2 \mathrm{~g} / \mathrm{L} \mathrm{K}_{2} \mathrm{HPO}_{4}, 0.2 \mathrm{~g} / \mathrm{L} \mathrm{MgSO}_{4} \cdot 7 \mathrm{H}_{2} \mathrm{O}, 0.14 \mathrm{~g} / \mathrm{L} \mathrm{MnSO}_{4} \cdot \mathrm{H}_{2} \mathrm{O}$, and $1 \mathrm{~mL} / \mathrm{L}$ vitamin solution ${ }^{b}[19]$
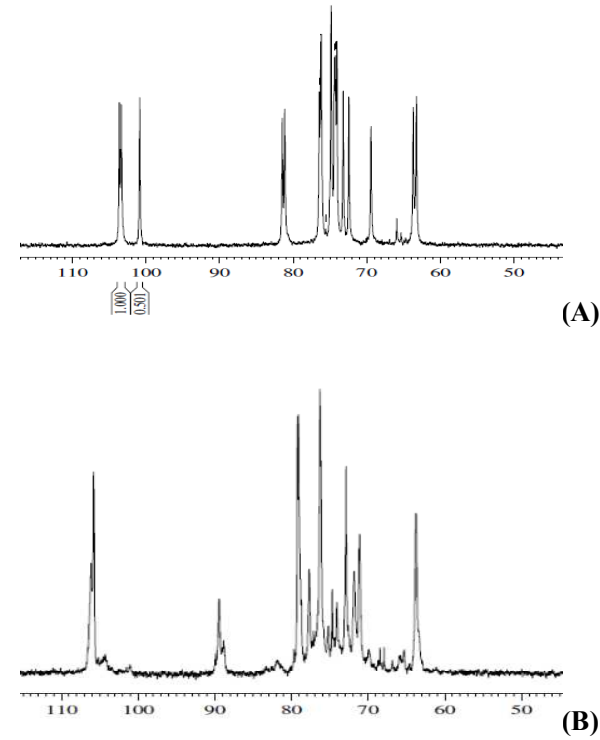

\subsection{EPS Prebiotic Characteristics}

As one of the criteria for classifying a food ingredient as a prebiotic is resistance to gastric acid digestion and to hydrolysis by mammalian enzymes, in vitro treatment with $0.1 \mathrm{M} \mathrm{HCl}$ or with porcine pancreatic $\alpha$-amylase of all three sources of EPS were resistant to such treatments (Table 4). These results indicated that these polysaccharides should reach the intestine almost ( $>95 \%$ ) intact, thus meeting this requirement is part of a prebiotic.

Figure 1. ${ }^{13} C$-NMR spectra of EPS from O. dipterigena $B C C 2073$ (A), and P. tenuipes BCC 2656 (B)

Table 4. Hydrolysis resistance of fungal EPS

\begin{tabular}{lcc}
\hline Fungus & Acid hydrolysis (\%) $^{\mathbf{c}}$ & Enzyme hydrolysis (\%) $^{\mathbf{c}}$ \\
\hline B. bassiana BCC 2692 & 0.20 & 0.84 \\
O. dipterigena BCC 2073 & 0.00 & 0.00 \\
P. tenuipes BCC 2656 & 2.09 & 0.00 \\
\hline
\end{tabular}




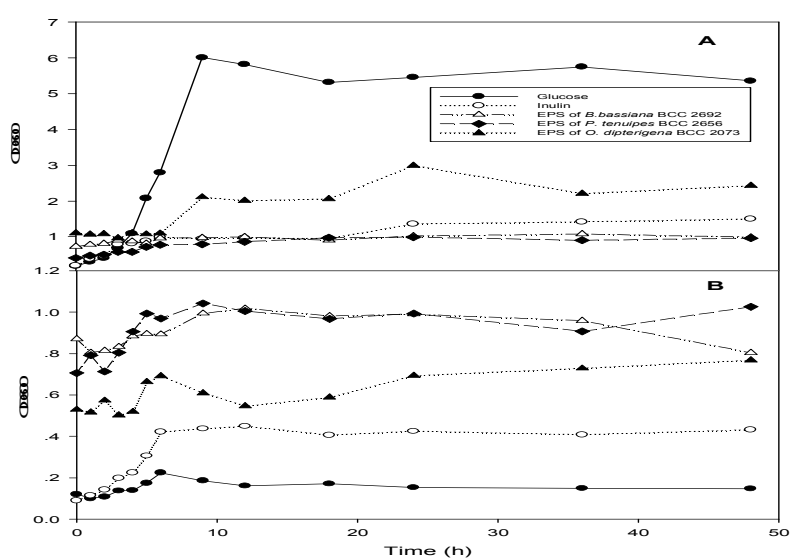

Figure 2. Growth of L. acidophilus BCC 13839 9A) and B. animalis ATCC 25527 (B) on three entomopathogenic fungal EPS sources, glucose and inulin as sole carbon source. The cultivation was performed in $1 \mathrm{~L}$ bioreactor at $37^{\circ} \mathrm{C}$ for $48 \mathrm{~h}$ under anaerobic condition.

Another criterion of a prebiotic is the ability to act as nutrient source for intestinal microflora. Thus, two different probiotics were cultivated on the three sources of EPS as carbon source in comparison to glucose and inulin. With L. acidophilus BCC 13839, the highest growth was observed on glucose after $10 \mathrm{~h}$ of cultivation (Figure $2 \mathrm{~A}$ ). Among the three EPS samples, that from O. dipterigena BCC 2073 supported the best growth of L. acidophilus BCC 13839, while the other two types of EPS supported lower growth, but comparable to that of inulin. Whereas growth of B. animalis ATCC 25527 on different substrates after $10 \mathrm{~h}$ of cultivation was P. tenuipes $\mathrm{BCC} 2556 \mathrm{EPS} \cong \mathrm{B}$. bassiana BCC 2692 EPS > O. dipterigena BCC 2073 EPS > inulin $>$ glucose (Figure 2B). However, when viability of the bacteria was examined, that of L. acidophilus BCC 13839 at $10 \mathrm{~h}$ of cultivation was on O. dipterigena BCC 2073 EPS $>$ inulin $>$ glucose $>$ B. bassiana BCC $2692 \cong$ P. tenuipes BCC 2656 EPS (Figure 3A). In addition, the results showed that viability of the lactic acid bacteria on inulin and glucose noticeably decreased after $24 \mathrm{~h}$ growth and $36 \mathrm{~h}$, respectively, whereas viability was steady when using all three sources of EPS. For B. animalis ATCC 25527, its viability when cultivated on glucose, inulin and EPS of O. dipterigena BCC 2073 was comparable, but lower than the other two sources of EPS (Figure 3B). Lactic acid production of L. acidophilus BCC 13839 on various studied substrates at $10 \mathrm{~h}$ growth was glucose $>$ P. tenuipes BCC 2656 EPS $>$ B. bassiana BCC 2692 EPS $>$ O. dipterigena BCC 2073 EPS > inulin (Figure 4A). It is notable that on glucose, lactic acid production decreased after $10 \mathrm{~h}$ of cultivation, whereas on inulin lactic acid level remained constant after $6 \mathrm{~h}$. Moreover, the production of lactic acid on B. bassiana BCC 2692 EPS continuously decreased after 12 $\mathrm{h}$ until no lactic acid was detected at $48 \mathrm{~h}$ of cultivation. Regarding B. animalis ATCC 25527, lactic acid production at $10 \mathrm{~h}$ is as follows: inulin $>\mathrm{B}$. bassiana BCC $2692 \mathrm{EPS}>$ glucose (Figure 4B). On inulin, lactic acid level remained constant after $12 \mathrm{~h}$ of cultivation, whereas on glucose its lactic acid production continuously rose after $5 \mathrm{~h}$. There was no lactic acid detected when EPS of O. dipterigena BCC
2073 and P. tenuipes BCC 2656 used as substrate.

\section{Discussion}

Prebiotics have to be compounds non-digestible by stomach acid and enzymes and can stimulate growth of essential bacteria in the gastrointestinal tract of animals and humans. Most prebiotics are limited in their persistence to the distal colon and are predominantly fermented in the proximal colon or metabolized by microbial flora saccharolytic enzymes [7-8, 33-34, 37, 39]. This study showed that the exopolysaccharides produced by three different entomopathogenic fungi exhibit prebiotic properties. The chemical structures of these EPS were typical of $\beta$-glucans with varying size distributions $[19,23$, 26]. All EPS produced by B. bassiana BCC 2692, $O$. dipterigena BCC 2073, and P. tenuipes BCC 2656 are non-cytotoxic to human cells [23]. Although it was found that most of the commercialized prebiotics, such as insulin, fructo-oligosaccharides (FOS), galacto-oligosaccharides (GOS), and soybean oligosaccharides have degree of polymerization (DP) in the range of oligosaccharides (DP < 25) [24], some polysaccharides like glucans from fruit bodies of mushrooms have been also reported to possess potential prebiotic activity [40].

The higher production of exobiopolymer of $P$. tenuipes BCC 2656 in bioreactor was obtained in comparison to $B$. bassiana BCC 2692 due to the physical conditions such as aeration, agitation, and dissolved oxygen were not optimized in this study. Furthermore, the production of EPS by $B$. bassiana BCC 2692 in bioreactor was lower than in shake flask (two-level fractional factorial design) due to agitation of the propeller and rotation speed of the shaker might affected the fungal mycelial morphology and influence the production of EPS. Further agitation rate must be optimized for this fungus in order to obtain higher production of EPS.

High production of EPS from O. dipterigena BCC 2073 is very attractive for a fermentation process as its EPS yield under the optimized conditions is 20 times higher than that on potato dextrose broth (PDB, $2.53 \mathrm{~g} / \mathrm{L}$ and $13.2 \mathrm{~g} / \mathrm{L}$ on optimal medium) [19]. Although the fermentation in this report was carried out as a batch process, production can be increased using other fermentation processes such as a well mix bioreactor [43], which can reduce problems of high viscosity, low oxygen transfer rate, and low sugar consumption rate. Although growth of L. acidophilus BCC 13839 on glucose and inulin were higher than that on entomopathogenic EPS, cell viability was compromised in long term cultivation. For B. animalis ATCC 25527, all three entomopathogenic fungal EPS supported and maintained a better bacterial growth in comparison with glucose and inulin. These results indicate that these exopolysaccharides showed prebiotic properties that could maintain the growth of probiotics in gastrointestinal tract of animals and humans. It is worth noting that there was no lactic acid detected when EPS of $O$. dipterigena BCC 2073 and P. tenuipes BCC 2656 used as substrate, which contrast with that when EPS of B. bassiana BCC 2692 used as 
substrate. This probably attributes to differences in $\beta$-glucan structure of these EPS since it has been found that EPS of B. bassiana BCC 2692 possesses less branched structure, compared with the other two ones (data not shown). Since EPS with less complex molecular structure might be easily metabolized as carbon source by probiotics.

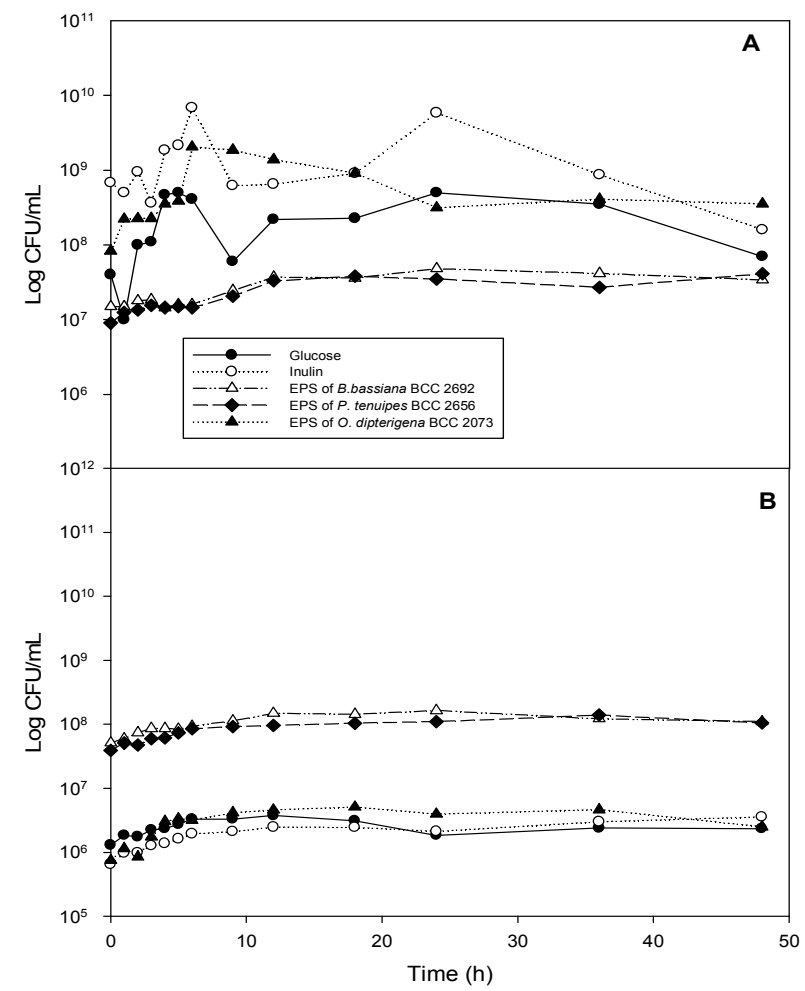

Figure 3. Viability of L. acidophilus BCC 13839 (A) and B. animalis ATCC 25527 (B) cultivated on three entomopathogenic fungal EPS, glucose and inulin as sole carbon source.

In addition, the variation in lactic acid production was possibly due to different utilization of carbon sources by the probiotics [38]. L. acidophilus BCC 13839 metabolized all carbon sources to produce lactic acid better than $B$. animalis ATCC 25527. The more end-product of lactic acid produced, the more EPS metabolized by the probiotics [44]. Furthermore, the absence of lactic acid produced by $B$. animalis ATCC 25527 on some substrates might be due to the bacteria produced acetic acid rather than lactic acid [44].

\section{Conclusion}

With the ability to obtain high production using optimized growth medium formulation, these entomopathogenic fungal EPS could be a promising prebiotic in the food and feed industries. $\beta$-Glucans from three strains of entomopathogenic fungi demonstrated prebiotic characteristics; non-digestibility by $0.1 \mathrm{M} \mathrm{HCl}$ and by porcine pancreatic $\alpha$-amylase, non-cytotoxic to human cells and ability to promote the in vitro growth of two different studied probiotics (Lactobacillus acidoplilus BCC 13839 and Bifidobacterium animalis ATCC 25527). Thus, these
EPS have a potential as alternative sources of prebiotics, which can be produced at an industrial scale through fermentation.

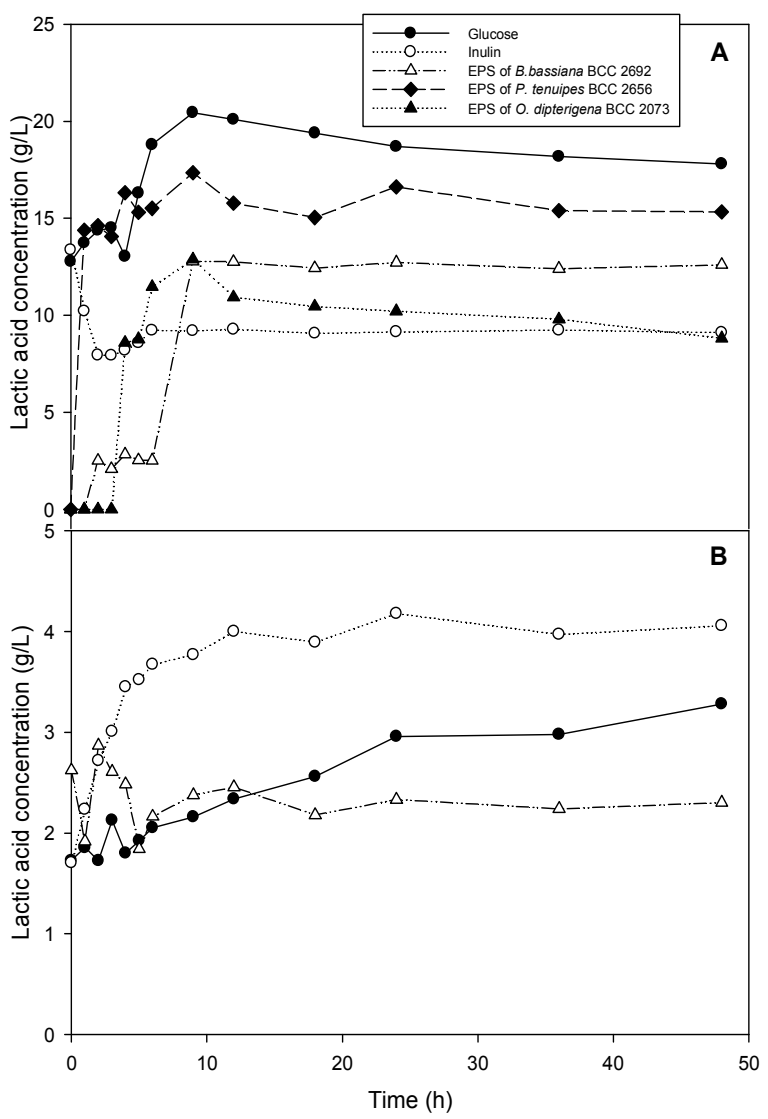

Figure 4. Lactic acid production of L. acidophilus BCC 13839 (A) and B. animalis ATCC 25527 (B) cultivated on three entomopathogenic fungal EPS, glucose and inulin as sole carbon source.

\section{Acknowledgements}

This project was financially supported by National Metal and Materials Technology Center (MTEC), National Science and Technology Development Agency, Thailand.

\section{References}

[1] O. Bañuelos, L. Fernández, J.M. Corral, M. Valdivieso-Ugarte, J.L. Adrio, and J. Velasco, "Metabolism of prebiotic products containing b (2-1) fructan mixtures by two Lactobacillus strains," Anaerobe, vol. 14, pp.:184-189, June 2008.

[2] D. Bosscher, J. Van Loo, and A. Franck, "Inulin and oligofructose as prebiotics in the prevention of intestinal infections and diseases," Nutr. Res. Rev., vol. 19, pp. 216-226, December 2006.

[3] E. Bruzzese, M. Volpicelli, V. Squeglia, D. Bruzzese, F. Salvini, M. Bisceglia, P. Lionetti, M. Cinquetti, G. Iacono, S. Amarri, and A. Guarino, "A formula containing galacto- and fructo-oligosaccharides prevents intestinal and 
extra-intestinal infections: an observational study," Clin. Nutr., vol. 28, pp. 156-161, April 2009.

[4] M.F. Chaplin, "Monosaccharides," in Carbohydrate analysis: a practical approach, M.F. Chaplin and J.F. Kennedy, Eds. Oxford: IRL Press, 1986, pp. 1-36.

[5] W. Chen, Z. Zhao, S. F. Chen, and Y. Q. Li, "Optimization for the production of exopolysaccharide from Fomes fomentarius in submerged culture and its antitumor effect in vitro," Bioresour. Technol., vol. 99, pp. 3187-3194, May 2008.

[6] G.V. Coppa, L. Zampini, T. Galeazzi, and O. Gabrielli, "Prebiotics in human milk: a review," Dig. Liver Dis., vol. 38, pp. S291-S294, December 2006.

[7] J.H. Cummings, G.T. Macfarlane, and H.N. Englyst, "Prebiotic digestion and fermentation," Am. J. Clin. Nutr., vol. 73, pp. 415S-420S, February 2001.

[8] L.C. Douglas and M.E. Sanders, "Probiotics and prebiotics in dietetics practice," Am. J. Clin. Nutr., vol. 108, pp. 510-521, March 2008.

[9] Falony, G., A. Verschaeren, F. De Bruycker, V. De Preter, K. Verbeke, F. Leroy, and L. De Vuyst, "In vitro kinetics of prebiotic inulin-type fructan fermentation by butyrate-producing colon bacteria: implementation of online gas chromatography for quantitative analysis of carbon dioxide and hydrogen gas production," Appl. Environ. Microbiol., vol. 75, pp. 5884-5892, September 2009.

[10] G. Falony, K. Lazidou, A. Verschaeren, S. Weckx, D. Maes, and L. De Vuyst, "In vitro kinetic analysis of fermentation of prebiotic inulin-type fructans by Bifidobacterium species reveals four different phenotypes," Appl. Environ. Microbiol., vol. 75, pp. 454-461, September 2009.

[11] K. Ghosh, K. Chandra, A.K. Ojha, and S.S. Islam, "NMR and MALDI-TOF analysis of a water-soluble glucan from an edible mushroom Volvariella diplasia," Carbohydr. Res., vol. 343, pp. 2834-2840, November 2008.

[12] J.T.M. Hamilton-Miller, "Probiotics and prebiotics in the elderly,” Postgrad. Med. J., vol. 80, pp. 447-451, January 2004.

[13] D.C. Hernot, T.W. Boileau, L.L. Bauer, I.S. Middelbos, M.R Murphy, K.S. Swanson, and G.C.Jr. Fahey, "In vitro fermentation profiles, gas production rates, and microbiota modulation as affected by certain fructans, galactooligosaccharides, and polydextrose," J. Agric. Food. Chem., vol. 57, pp. 1354-1361, February 2009.

[14] S.J. Jung, R. Houde, B. Baurhoo, X. Zhao, and B.H. Lee, "Effects of galacto-oligosaccharides and a Bifidobacteria lactis-based probiotic strain on the growth performance and fecal microflora of broiler chickens," Poult. Sci., vol. 87, pp. 1694-1699, September 2008.

[15] G. Kelly, "Inulin-type prebiotics-a review: part 1," Altern. Med. Rev., vol. 13, pp. 315-29, December 2008.

[16] G. Kelly, "Inulin-type prebiotics: a review (Part 2)," Altern. Med. Rev., vol. 14, pp. 36-55, March 2009.

[17] Y.T. Kim, E.H. Kim, C. Cheong, D.L. Williams, C.W. Kim, and S.T. Lim, "Structural characterization of -D-(1-3, 1-6)-linked glucans using NMR spectroscopy," Carbohydr.
Res., vol. 328, pp. 331-341, September 2000.

[18] M. Kiyohara, A. Tachizawa, M. Nishimoto, M. Kitaoka, H. Ashida, and K. Yamamoto, "Prebiotic effect of lacto-N-biose I on bifidobacterial growth," Biosci. Biotechnol. Biochem., vol. 73, pp. 1175-1179, May 2009.

[19] K. Kocharin, P. Rachathewee, J.J. Sanglier, and W. Prathumpai, "EBP production of Ophiocordyceps dipterigena BCC 2073: optimization, production in bioreactor and characterization," BMC Biotechnol. vol .12, pp. 10:51, July 2010.

[20] S. Kolida and G.R. Gibson, "Prebiotic capacity of inulin-type fructans," J. Nutr., vol. 137, pp. 2503S-2506S, November 2007.

[21] D. Li, J.M. Kim, Z. Jin, and J. Zhou, "Prebiotic effectiveness of inulin extracted from edible burdock," Anaerobe., Vol. 14, pp. 29-34, February 2008.

[22] A.R. Lomax and P.C. Calder' "Prebiotics, immune function, infection and inflammation: a review of the evidence," Br. J. Nutr., vol. 101, pp. 633-658, March 2009.

[23] S. Madla, P. Methacanon, M. Prasitsil, and K. Kirtikara, "Characterization of biocompatible fungi-derived polymers that induce IL-8 production," Carbohydr. Polym., Vol. 59, pp. 275-280, February 2005.

[24] T.S. Manning and G.R. Gibson, "Prebiotics," Best Pract. Res. Clin. Gastroentero., vol. 18, pp. 287-298, April 2004.

[25] W.H. McNeely and K.S. Kang, "Xanthan and other biosynthetic gums," in Industrial Gums, R.L. Whistler, J.N. BeMiller, Eds. New York: Academic, 1973, pp. 473-497.

[26] P. Methacanon, S. Madla, K. Kirtikara, and M. Prasitsil, "Structural elucidation of bioactive fungi-derived polymers," Carbohydr. Polym., vol. 60, pp. 199-203, July 2008.

[27] R.P. Oliveira, A.C. Florence, R.C. Silva, P. Perego, A. Converti, L.A. Gioielli, and M.N. Oliveira, "Effect of different prebiotics on the fermentation kinetics, probiotic survival and fatty acids profiles in nonfat symbiotic fermented milk," Int. J. Food Microbiol., vol. 128, pp. 467-472, January 2009.

[28] X. Pan, T. Wu, L. Zhang, L. Cai, and Z. Song, "Influence of oligosaccharides on the growth and tolerance capacity of lactobacilli to simulated stress environment," Lett. Appl. Microbiol., vol. 48, pp. 362-367, March 2009.

[29] X.D. Pan, F.Q. Chen, T.X. Wu, H.G. Tang, and Z.Y. Zhao, "Prebiotic oligosaccharides change the concentrations of short-chain fatty acids and the microbial population of mouse bowel,” J. Zhejiang Univ. Sci. B., vol. 10, pp. 258-263, April 2009.

[30] H. Parracho, A.L. McCartney, and G.R. Gibson, "Probiotics and prebiotics in infant nutrition," Proc. Nutr. Soc., vol. 66, pp. 405-411, August 2007.

[31] Y. Peng, L. Zhang, F. Zeng, and Y. Xu, "Structure and antitumor activity of extracellular polysaccharides from mycelium," Carbohydr. Polym., vol. 54 pp. 297-303, November 2003.

[32] A. Pompei, L. Cordisco, S. Raimondi, A. Amaretti, U.M. Pagnoni, D. Matteuzzi, and M. Rossi, "In vitro comparison 
of the prebiotic effects of two inulin-type fructans," Anaerobe, vol. 14, 280-286, November 2008.

[33] M.B. Roberfroid, "Prebiotics: preferential substrates for specific germs?," Am. J. Clin. Nutr., vol. 73, pp. 406S-409S, February 2001.

[34] M.B. Roberfroid, "Prebiotics: the concept revisited," J. Nutr., vol. 137, pp. 830S-837S. March 2007.

[35] N. Salazar, M. Gueimonde, A.M. Hernandez-Barranco, P. Ruas-Madiedo, G. Clara, and L. Reyes-Gavilan, "Exopolysaccharides produced by intestinal Bifidobacterium strains act as fermentable substrates for human intestinal bacteria," Appl. Environ. Microbiol., vol. 74, pp. 4737-4745, August 2008.

[36] N. Salazar, P. Ruas-Madiedo, S. Kolida, M. Collins, R. Rastall, G. Gibson, and C.G. de Los Reyes-Gavilán, "Exopolysaccharides produced by Bifidobacterium longum IPLA E44 and Bifidobacterium animalis subsp. lactis IPLA R1 modify the composition and metabolic activity of human fecal microbiota in pH-controlled batch cultures," Int. J. Food Microbiol., vol. 135, pp. 260-267, November 2009.

[37] D.M. Saulnier, J.K. Spinler, G.R. Gibson, and J. Versalovic, "Mechanisms of probiosis and prebiosis: considerations for enhanced functional foods," Curr. Opin. Biotechnol., vol. 20, pp. 135-141, April 2009.

[38] P. Su, A. Henriksson and H. Mitchell, "Selected prebiotics support the growth of probiotic mono-cultures in vitro," Anaerobe, vol. 13, pp.134-139, June-August 2007.

[39] K. Swennen, C.M. Courtin, and J.A. Delcour, "Non-digestible oligosaccharides with prebiotic properties," Crit. Rev. Food Sci. Nutr., vol. 46, pp. 459-471, June 2006.

[40] A. Synytsya, K. Míčkova, A. Synytsya, I. Jablonský, and J. Spěváček, "Glucans from fruit bodies of cultivated mushrooms Pleurotus ostreatus and Pleurotus eryngii: Structure and potential prebiotic activity," Carbohydr. Polym., vol. 76, pp. 548-556, May 2009.

[41] P. Trevisi, S. De Filippi, L. Minieri, M. Mazzoni, M. Modesto, B. Biavati, and P. Bosi, "Effect of fructo-oligosaccharides and different doses of Bifidobacterium animalis in a weaning diet on bacterial translocation and Toll-like receptor gene expression in pigs," Nutr. Vol. 24, 1023-1029, October 2008.

[42] L. Vuyst and B. Degeest, "Heteropolysaccharides from lactic acid bacteria," FEMS Microbiol. Rev., vol. 23, pp. 153-177, April 1999.

[43] C.P. $\mathrm{Xu}$ and J.W. Yun, "Influence of aeration on the production and the quality of the exopolysaccharides from Paecilomyces tenuipes C240 in a stirred-tank fermenter," Enz. Microb. Technol., vol. 35, pp. 33-39, July 2004.

[44] S.K. Yeo and M.T. Liong, "Effect of prebiotics on viability and growth characteristics of probiotics in soymilk," J. Sci. Food Agric., vol. 90, pp. 267-275, January 2010. 